\title{
Blood Pressure Variability in Obstructive Sleep Apnoea: Data from 4 Randomised Controlled CPAP Withdrawal Trials
}

\author{
Franziska Lettau ${ }^{a}$ Esther I.Schwarz ${ }^{\mathrm{a}}$ John R. Stradling ${ }^{c}$ Malcolm Kohlera, b \\ ${ }^{\mathrm{a}}$ Department of Pulmonology, University Hospital Zurich, and ${ }^{\mathrm{b}}$ Center for Interdisciplinary Sleep Research, \\ University of Zurich, Zurich, Switzerland; ' $N$ ational Institute for Health Research (NIHR) Oxford Biomedical Research \\ Centre based at Oxford University Hospitals, NHS Foundation Trust and University of Oxford, Oxford, UK
}

\section{Keywords}

Obstructive sleep apnoea - Continuous positive airway pressure $\cdot$ Blood pressure variability

\begin{abstract}
Background: Increased daytime blood pressure variability (BPV) is associated with cardiovascular risk. Preliminary data suggest that obstructive sleep apnoea (OSA) might contribute to increased daytime BPV. Objective: The aim of this study was to evaluate the effect of continuous positive airway pressure (CPAP) therapy withdrawal on daytime BPV. Methods: A total of 183 patients previously diagnosed with OSA and treated with CPAP were randomised to either continue or withdraw from CPAP within 4 trials. Office morning BP was measured in triplicate at baseline and at follow-up (day 14). In addition, the participants performed BP measurements at home on a daily basis (days 1-13). The main outcome of interest was the treatment effect on within-visit BPV expressed as the standard deviation (SD) of the triplicate measurements. Additional outcomes included morning home BPV and day-to-day home BPV. Results: Within-visit variability in systolic BP significantly increased in response to recurrence of OSA in the CPAP withdrawal group (difference between groups in SD of systolic BPV, $+1.14 \mathrm{~mm} \mathrm{Hg}, 95 \% \mathrm{Cl}$ $+0.20 /+2.09, p=0.02$ ). There was no statistically significant
\end{abstract}

\section{KARGER}

(C) 2017 S. Karger AG, Basel

E-Mail karger@karger.com

www.karger.com/res effect on within-visit variability in diastolic BP $(p=0.38)$ or heart rate $(p=0.07)$. Neither morning home BP variability (systolic BPV, $p=0.81$; diastolic BPV, $p=0.46$ ) nor day-to-day variability in home BP measurements (systolic BPV, $p=0.61$; diastolic BPV, $p=0.58$ ) differed significantly between the groups. Conclusion: CPAP withdrawal results in a minor increase in within-visit variability in office systolic BP, but it has no effect on home BPV or day-to-day BPV. Although the treatment effect may be blunted by antihypertensives, it is unlikely that OSA contributes to cardiovascular risk via elevated daytime BPV.

(c) 2017 S. Karger AG, Basel

\section{Introduction}

Obstructive sleep apnoea (OSA) has been identified as a common factor associated with hypertension and cardiovascular disease (CVD), although potential causal mechanisms have not been fully elucidated [1]. The prevalence of OSA is likely to further increase as a result of increasing obesity [2]. Observational and populationbased epidemiological studies have shown that untreated moderate-to-severe OSA is associated with hypertension and adverse cardiovascular outcome [3-7]. However, randomised controlled trials on the effects of continuous

Prof. Malcolm Kohler

Chair Respiratory Medicine, Department of Pulmonology, University Hospital Zurich Rämistrasse 100

CH-8091 Zurich (Switzerland)

E-Mail malcolm.kohler@usz.ch 
positive airway pressure (CPAP) therapy have so far only established a causal association between OSA and diurnal hypertension [8].

Hypertension is an established risk factor for CVD [9]. In recent years, not only sustained blood pressure (BP) elevation itself but also BP variability (BPV) have been recognised as important predictors of CVD [10-12]; there seems to be a connection between high BPV and increased cardiovascular morbidity and mortality, even in patients with well-controlled BP [11-14]. These findings have been linked to alteration of vascular reactivity due to, amongst other factors, increased arterial stiffness and endothelial dysfunction [15-17]. Similarly, impaired endothelial function has been observed in OSA patients [18-20], possibly linking the underlying pathophysiology of OSA and elevated BPV. Furthermore, the consequences of OSA involve numerous mechanisms such as autonomic dysregulation and increased sympathetic activity, thus linking OSA to elevated BP levels and potentially to increased BPV [21, 22]. One might, therefore, hypothesise that not only elevated BP levels but also increased BPV may be caused by OSA and contribute to the associated adverse cardiovascular outcomes.

An association between the severity of OSA and BPV has previously been described in physiologic and observational studies $[23,24]$. While it could be shown that CPAP therapy effectively abolishes OSA [25], improves endothelial function [26, 27], and reduces BP [8], there are controversial data on the effect of CPAP therapy on daytime BPV $[28,29]$. Although there have been studies on the association of OSA with BPV, evidence from randomised controlled interventional trials is missing.

Short-term CPAP therapy withdrawal has been shown to result in the recurrence of OSA and its consequences such as increased BP, sympathetic activity, and impaired endothelial function $[20,30]$. Therefore, we considered this study design suitable to evaluate the effects of CPAP withdrawal on BPV. We hypothesised that the recurrence of OSA in response to therapy withdrawal would result in an increase in within-visit BPV as well as in short-term morning home BPV and intermediate-term day-to-day BPV.

\section{Subjects and Methods}

\section{Trial Design and Intervention}

Four randomised controlled trials, which allocated CPAPtreated patients to either continue or withdraw from CPAP for 2 weeks, were conducted in Zurich and Oxford between 2010 and 2015 [20, 30-32]. Patients registered in the sleep database of the
Sleep Disorders Centre and Pulmonary Division of the University Hospital Zurich, Zurich, Switzerland, and of the Centre for Respiratory Medicine, Oxford, UK, were recruited. Baseline examinations on therapeutic CPAP therapy were performed in both study arms. The morning after the baseline sleep studies, the patients were randomly assigned to either continue therapeutic CPAP or withdraw from CPAP (subtherapeutic sham CPAP or non-therapeutic nasal device) and returned 2 weeks later for the follow-up sleep study on the assigned treatment. Morning BP was measured daily in triplicate during the study period. The studies were approved by the research ethics committees in Zurich (EK-1600, KEK-ZH-2012-051) and Oxford (11/NW/0370). Written informed consent was obtained from all participants. The trials were registered prior to commencement (ClinicalTrials.gov NCT01332175, NCT01797653, and NCT02050425; controlledtrials.com: ISRCTN 93153804).

\section{Participants}

Subjects with known OSA were recruited from the Sleep Disorders Centre and Pulmonary Division of the University Hospital Zurich and from the Centre for Respiratory Medicine in Oxford. Patients aged 20-75 years with an oxygen desaturation index (ODI) of $\geq 10 / \mathrm{h}[20,30]$ or $20 / \mathrm{h}[31,32]$ in their in-laboratory sleep study at the time of diagnosis were eligible if they had been treated with CPAP for at least 1 year (compliance of $\geq 4 \mathrm{~h} /$ night) and currently had an ODI $>10 / \mathrm{h}[20,30]$ or $>20 / \mathrm{h}[31,32]$ in a nocturnal pulse oximetry assessment on the last night of a 4-night period off CPAP treatment. Exclusion criteria were ventilatory failure, Cheyne-Stokes respiration, unstable or untreated vascular disease, inadequately controlled arterial hypo- or hypertension, professional driving, and a previous traffic accident associated with sleepiness.

\section{Outcomes}

The main outcome of interest was the treatment effect on within-visit BPV (standard deviation [SD] of 3 repeated office BP measurements [day 0 and day 14]). Other outcomes of interest were short-term morning home BPV (mean daily SD of 3 repeated home BP measurements over 2 weeks: $\left[\mathrm{SD}_{\text {triplet } 1}+\mathrm{SD}_{\text {triplet } 2}+\ldots+\right.$ $\left.\mathrm{SD}_{\text {triplet13 }}\right] / 13$ ) and intermediate-term day-to-day BPV (SD of daily mean home $\mathrm{BP}$ over 2 weeks: $\mathrm{SD}$ of $\left.\left[\mathrm{BP}_{1}+\mathrm{BP}_{2}+\ldots+\mathrm{BP}_{13}\right]\right)$, as well as heart rate (HR) variability over the whole study period and effects on sleep apnoea severity (ODI).

After the baseline and follow-up sleep studies, morning office $\mathrm{BP}$ and HR were measured in triplicate (1-min intervals) with a validated standard digital automatic monitor (Omron Healthcare Co., Kyoto, Japan). In addition, the patients measured their home morning BP and HR in triplicate with the same device each day during the study period. The measurements were performed according to a standardised protocol: in a sitting position after a period of rest of $\geq 5 \mathrm{~min}$, immediately after getting up, before breakfast, and before intake of antihypertensive drugs, with 1-min intervals between the 3 measurements. The sleep studies and therapy devices (CPAP, subtherapeutic CPAP, and ineffective nasal devices) have previously been described [20, 30-32].

\section{Randomisation and Blinding}

The methods of randomisation and blinding have been reported previously [20,30-32]. The patients and investigators were blinded to treatment allocation. $\begin{array}{ll}312 & \text { Respiration } 2017 ; 93: 311-318 \\ & \text { DOI: } 10.1159 / 000465528\end{array}$
Lettau/Schwarz/Stradling/Kohler 


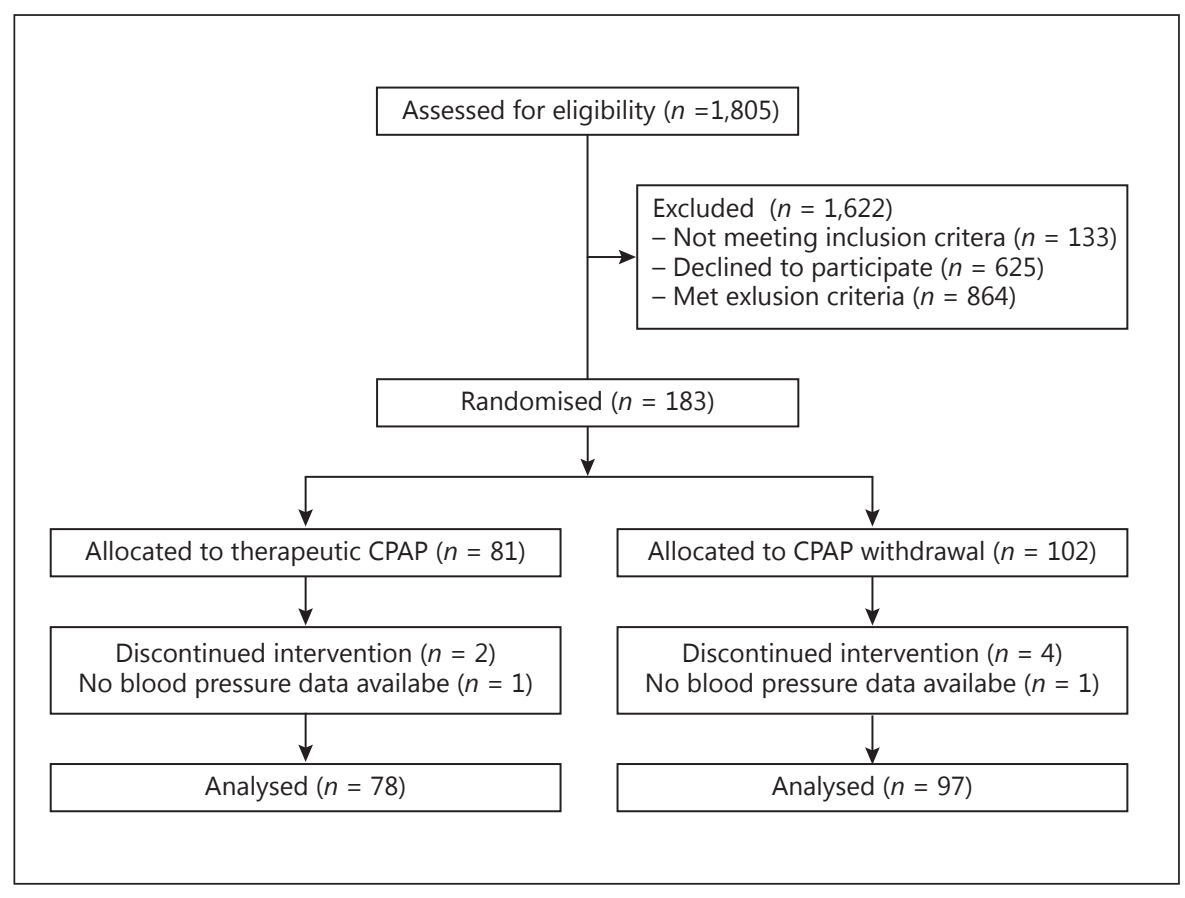

Fig. 1. Patient selection flow chart.

\section{Statistical Methods}

A per-protocol analysis was performed. The KolmogorovSmirnov test was used to test for normality of data distribution. For the main outcome of interest, between-group differences in change of within-visit BPV from baseline to follow-up were adjusted for baseline differences using linear regression models. For the additional outcomes, group differences between the patients randomised to continue and those randomised to withdraw from therapeutic CPAP were analysed with independent $t$ tests for normally distributed and with Mann-Whitney U tests for non-normally distributed data. Analyses were conducted at a 2-sided significance level of $<0.05$. Statistica (version 12 for Windows; StatSoft Inc., Tulsa, OK, USA) was used for the statistical analyses.

\section{Results}

\section{Participants}

Of the 183 participants randomised to either continue therapeutic CPAP $(n=81)$ or withdraw from CPAP $(n=$ 102), 175 completed the trial and provided BP data (Fig. 1). Two patients in the therapeutic CPAP and 4 patients in the withdrawal group discontinued the intervention. One participant in each group did not measure $\mathrm{BP}$ on a daily basis. Recruitment for the first trial [20] started in August 2009 and the last patient's visit [32] took place in August 2015. The baseline characteristics of the 2 treatment groups were comparable and are shown in Table 1.

Blood Pressure Variability in OSA
Table 1. Baseline patient characteristics

\begin{tabular}{lcc}
\hline & $\begin{array}{l}\text { Therapeutic } \\
\text { CPAP } \\
(n=78)\end{array}$ & $\begin{array}{l}\text { CPAP } \\
\text { withdrawal } \\
(n=97)\end{array}$ \\
\hline Age, years & $63.4 \pm 7.9$ & $63.5 \pm 8.9$ \\
Male sex, $n$ (\%) & $64(82)$ & $81(83.5)$ \\
BMI & $33.6 \pm 5.8$ & $33.5 \pm 5.9$ \\
Neck circumference, cm & $44.1 \pm 4.1$ & $44.0 \pm 4.1$ \\
Never smoker, $n(\%)$ & $38(48.7)$ & $39(40.2)$ \\
Current smoker, $n(\%)$ & $9(11.5)$ & $12(12.4)$ \\
Former smoker, $n(\%)$ & $31(39.7)$ & $46(47.4)$ \\
Hypertension, $n(\%)$ & $50(64.1)$ & $74(76.3)$ \\
Mean number of & & \\
$\quad$ antihypertensive drugs & $1.4 \pm 1.4$ & $1.6 \pm 1.4$ \\
Calcium antagonist, $n(\%)$ & $19(24.4)$ & $30(30.9)$ \\
Beta-blocker, $n$ (\%) & $19(24.4)$ & $24(24.7)$ \\
ACE inhibitor or ARB, $n(\%)$ & $40(51.3)$ & $60(61.9)$ \\
Diabetes, $n(\%)$ & $19(24.4)$ & $24(24.7)$ \\
Dyslipidaemia, $n(\%)$ & $31(39.7)$ & $36(37.1)$ \\
Original AHI, events/h & $44.0 \pm 21.5$ & $43.6 \pm 20.1$ \\
Original ODI, events/h & $37.3 \pm 18.6$ & $37.6 \pm 18.0$ \\
Original ESS score & $13.8 \pm 3.3$ & $13.9 \pm 3.7$ \\
\hline
\end{tabular}

Data are presented as means \pm standard deviation unless otherwise mentioned. CPAP, continuous positive airway pressure; $\mathrm{BMI}$, body mass index; ACE, angiotensin-converting enzyme; $\mathrm{ARB}$, angiotensin receptor blocker; AHI, apnoea-hypopnoea index; ODI, oxygen desaturation index; ESS, Epworth Sleepiness Scale. 
Table 2. Treatment effects on within-visit office blood pressure and heart rate variability

\begin{tabular}{|c|c|c|c|c|c|c|c|}
\hline & \multicolumn{2}{|c|}{ Therapeutic CPAP $(n=78)$} & \multicolumn{2}{|c|}{ CPAP withdrawal $(n=97)$} & \multicolumn{3}{|c|}{ Treatment effect ${ }^{1}$} \\
\hline & baseline & follow-up & baseline & follow-up & $\begin{array}{l}\text { difference in } \\
\text { change be- } \\
\text { tween groups }\end{array}$ & $95 \% \mathrm{CI}$ & $p$ value \\
\hline SD office SBP, mm Hg & $4.55(2.90)$ & $4.37(2.19)$ & $4.88(2.59)$ & $5.52(3.69)$ & +1.14 & $+0.20,+2.09$ & 0.02 \\
\hline SD office DBP, mm Hg & $3.26(2.26)$ & $3.48(2.44)$ & $3.04(1.93)$ & $3.82(2.91)$ & +0.36 & $-0.45,+1.18$ & 0.38 \\
\hline SD office HR, bpm & $2.38(2.05)$ & $1.98(1.79)$ & $1.86(1.36)$ & $2.58(2.72)$ & +0.67 & $-0.05,+1.39$ & 0.07 \\
\hline
\end{tabular}

Data are presented as means (SD) unless otherwise mentioned. CPAP, continuous positive airway pressure; SD, standard deviation; SBP, systolic blood pressure; DBP, diastolic blood pressure; HR, heart rate. ${ }^{1}$ Treatment effect adjusted for baseline differences.

Table 3. Longitudinal short- and intermediate-term home blood pressure and heart rate variability (days $1-13)$

\begin{tabular}{|c|c|c|c|c|c|}
\hline & $\begin{array}{l}\text { Therapeutic } \\
\text { CPAP }(n=78)\end{array}$ & $\begin{array}{l}\text { CPAP with } \\
\text { drawal }(n=97)\end{array}$ & $\begin{array}{l}\text { Difference } \\
\text { between groups }\end{array}$ & $95 \% \mathrm{CI}$ & $p$ value \\
\hline \multicolumn{6}{|c|}{ Short-term morning home BP and HR variability (days $1-13)^{1}$} \\
\hline SD SBP, mm Hg & $4.97(1.57)$ & $5.03(1.42)$ & +0.06 & $-0.39,+0.50$ & 0.81 \\
\hline SD DBP, mm Hg & $3.37(1.09)$ & $3.50(1.20)$ & +0.13 & $-0.21,+0.48$ & 0.46 \\
\hline SD HR, bpm & $2.19(1.01)$ & $2.32(1.19)$ & +0.13 & $-0.20,+0.47$ & 0.43 \\
\hline \multicolumn{6}{|c|}{ Intermediate-term day-to-day home BP and $H R$ variability (days $1-13)^{2}$} \\
\hline SD SBP, mm Hg & $6.88(2.45)$ & $7.06(2.33)$ & +0.19 & $-0.53,+0.90$ & 0.61 \\
\hline SD DBP, mm Hg & $4.73(1.70)$ & $4.59(1.53)$ & -0.14 & $-0.62,+0.35$ & 0.58 \\
\hline SD HR, bpm & $4.73(2.58)$ & $4.99(2.35)$ & +0.26 & $-0.48,+0.99$ & 0.49 \\
\hline
\end{tabular}

Data are presented as means (SD) unless otherwise mentioned. CPAP, continuous positive airway pressure; BP, blood pressure; HR, heart rate; SD, standard deviation; SBP, systolic blood pressure; DBP, diastolic blood pressure. ${ }^{1}$ Mean daily SD of 3 repeated home BP measurements over 2 weeks: $\left(\mathrm{SD}_{\text {triplet } 1}+\mathrm{SD}_{\text {triplet2 }}+\ldots+\mathrm{SD}_{\text {triplet13 }}\right) / 13 .{ }^{2} \mathrm{SD}$ of daily mean home BP over 2 weeks: $\mathrm{SD}$ of $\left(\mathrm{BP}_{1}+\mathrm{BP}_{2}+\ldots+\mathrm{BP}_{13}\right)$.

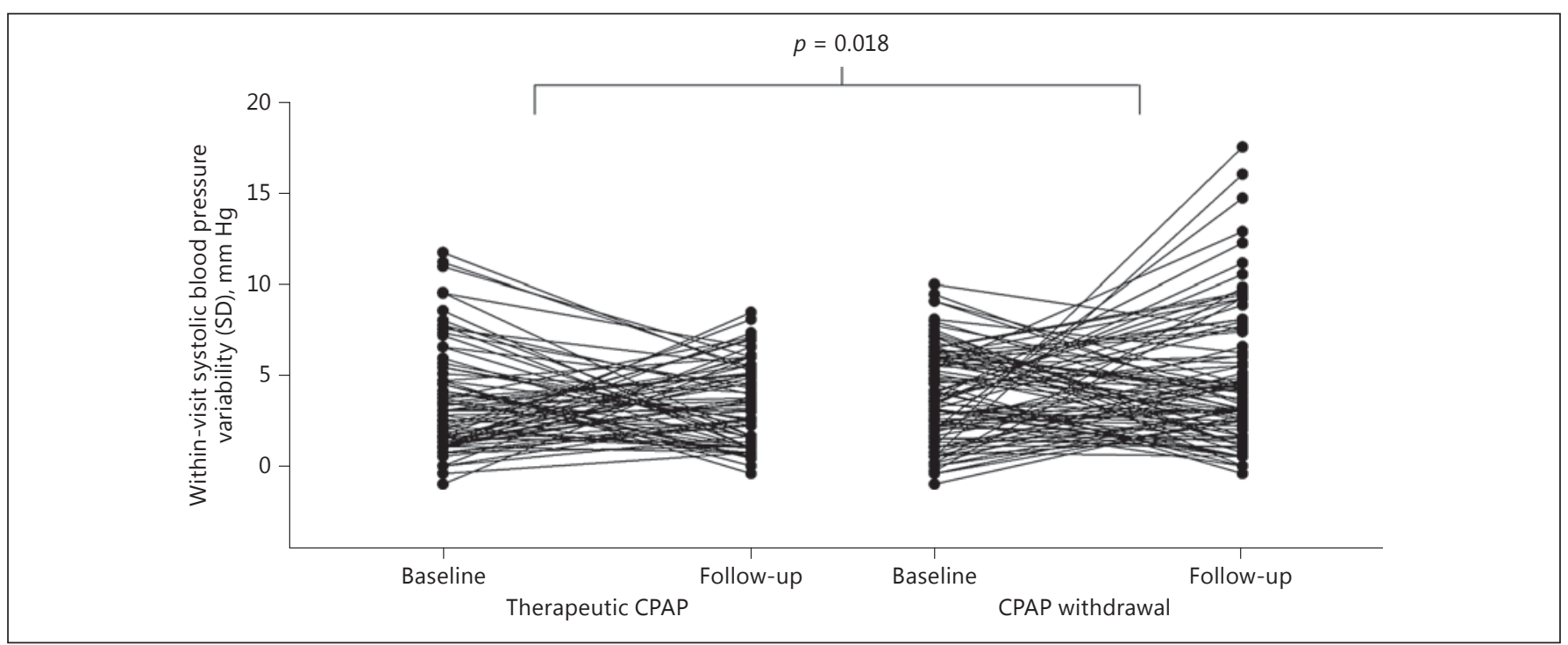

Fig. 2. Individual plots showing changes in within-visit blood pressure variability from baseline to follow-up in the group continuing therapeutic CPAP (left) and in the group withdrawn from CPAP therapy (right). CPAP, continuous positive airway pressure; SD, standard deviation. 
Table 4. Treatment effects on OSA severity and daytime sleepiness

\begin{tabular}{|c|c|c|c|c|c|c|c|}
\hline & \multicolumn{2}{|c|}{ Therapeutic CPAP $(n=78)$} & \multicolumn{2}{|c|}{ CPAP withdrawal $(n=84)$} & \multicolumn{3}{|c|}{ Treatment effect } \\
\hline & baseline & follow-up & baseline & follow-up & $\begin{array}{l}\text { difference in } \\
\text { change be- } \\
\text { tween groups }\end{array}$ & $95 \% \mathrm{CI}$ & $p$ value \\
\hline AHI & $2.4(2.3)$ & $3.2(3.8)$ & $2.8(3.4)$ & $33.1(19.3)$ & +29.4 & $25.1,33.7$ & $<0.001$ \\
\hline ODI & $2.9(4.0)$ & $2.9(3.6)$ & $3.3(3.9)$ & $34.4(19.3)$ & +31.1 & $26.9,35.4$ & $<0.001$ \\
\hline ESS & $7.2(3.5)$ & $7.0(4.0)$ & $7.6(3.6)$ & $9.5(4.4)$ & +2.1 & $1.2,2.9$ & $<0.001$ \\
\hline
\end{tabular}

Data are presented as means (standard deviation) unless otherwise mentioned. OSA, obstructive sleep apnoea; CPAP, continuous positive airway pressure; AHI, apnoea-hypopnoea index (in events/h); ODI, oxygen desaturation index (in events/h); ESS, Epworth Sleepiness Scale (in points; max. 24 points).

\section{Treatment Effect on Within-Visit Variability in $B P$ and $H R$}

CPAP withdrawal was associated with a statistically significant increase in within-visit variability in office systolic $\mathrm{BP}$ (between-group change in $\mathrm{SD},+1.14 \mathrm{~mm} \mathrm{Hg}$, $95 \% \mathrm{CI}+0.20 /+2.09, p=0.02)$, whereas it had no effect on variability in office diastolic BP $(+0.36 \mathrm{~mm} \mathrm{Hg}, 95 \% \mathrm{CI}$ $-0.45 /+1.18, p=0.38)$ compared with continuing therapeutic CPAP (Table 2; Fig. 2). There was a trend towards higher within-visit HR variability in the CPAP therapy withdrawal group compared to the group continuing therapeutic CPAP (between-group change in $\mathrm{SD},+0.67$ bpm, 95\% CI $-0.05 /+1.39, p=0.07$ ) (Table 2).

\section{Longitudinal Variability in Morning Home \\ $B P$ and $H R$}

Short-term variability in neither systolic home BP (difference between groups in SD, $0.06 \mathrm{~mm} \mathrm{Hg}, 95 \% \mathrm{CI}$ $-0.39 /+0.50, p=0.81$ ) nor diastolic home BP (difference between groups in $\mathrm{SD},+0.13 \mathrm{~mm} \mathrm{Hg}, 95 \% \mathrm{CI}-0.21 /+0.48$, $p=0.46$ ) or HR (difference between groups in $\mathrm{SD},+0.13$ bpm, 95\% CI $-0.20 /+0.47, p=0.43$ ) differed significantly between the 2 treatment groups over the study period (Table 3; Fig. 3).

\section{Longitudinal Day-to-Day Variability in Home \\ $B P$ and $H R$}

Day-to-day variability in systolic BP (difference between groups in SD $+0.19 \mathrm{~mm} \mathrm{Hg}, 95 \% \mathrm{CI}-0.53 /+0.90$, $p=0.61$ ), diastolic BP (difference between groups in SD, $-0.14 \mathrm{~mm} \mathrm{Hg}, 95 \% \mathrm{CI}-0.62 /+0.35, p=0.58)$, and HR (difference between groups in SD, $+0.26 \mathrm{bpm}, 95 \% \mathrm{CI}$ $-0.48 /+0.99, p=0.49$ ) did not differ significantly between therapeutic CPAP and CPAP withdrawal over the study period of 2 weeks (Table 3 ).

Blood Pressure Variability in OSA

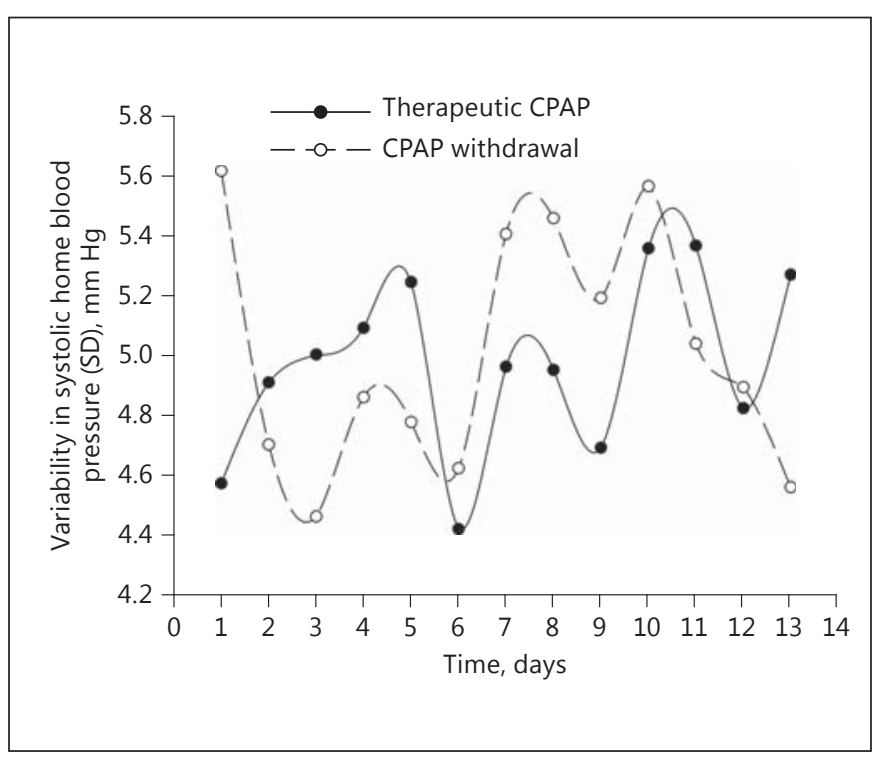

Fig. 3. Short-term variability in morning home systolic blood pressure after randomisation over the study period compared between the 2 groups. Each point represents the SD of a triplicate measurement of systolic home blood pressure (group mean) over 13 days after randomisation. CPAP, continuous positive airway pressure; $\mathrm{SD}$, standard deviation.

\section{Treatment Effect on OSA Severity and Daytime Sleepiness}

CPAP withdrawal was associated with a return of OSA (between-group change in apnoea-hypopnoea index, $+29.4,95 \% \mathrm{CI}+25.1 /+33.7, p<0.001)$ accompanied by an increase in daytime sleepiness (between-group change in Epworth Sleepiness Scale score, $+2.1,95 \%$ CI $+1.2 /+2.9, p<0.001)$ compared to therapeutic CPAP (Table 4). 


\section{Discussion}

This analysis of the effect of CPAP therapy withdrawal on daytime BPV found a slight increase in within-visit variability in systolic office $\mathrm{BP}$ in patients with moderateto-severe OSA. Although our data from several randomised controlled trials have demonstrated this modest effect of recurrence of OSA on short-term variability in office BP, it has not found an effect of OSA on short-term variability (morning BPV over 2 weeks) or intermediateterm variability (day-to-day variability over 2 weeks) in home BP. Furthermore, the treatment effect on systolic within-visit BPV seems rather modest and presumably is unlikely to be relevant [33].

Using the same trial design, previous CPAP withdrawal studies have found an increase in BP $[20,31,34]$ and sympathetic activity [20] and reductions in endothelial function $[20,27,30]$ accompanying the return of OSA, indicating a possible pathophysiological explanation for higher BPV. Thus, the marginally accentuated withinvisit variability in office systolic BP might mostly be explained by a higher susceptibility to the "white coat" effect [35] as a consequence of an increased sympathetic tone in untreated OSA.

To our knowledge, this is the largest data collection on treatment effects of CPAP therapy on daytime BPV in patients with OSA. Whether the findings regarding shortterm therapy withdrawal are comparable to effects of long-term CPAP therapy withdrawal remains uncertain. However, as previously shown [20], even short-term CPAP withdrawal usually leads to a rapid recurrence of OSA and is associated with distinct pathophysiological consequences such as impaired endothelial function, increased urinary catecholamine excretion, and elevation of both BP and HR. Treatment effects of CPAP therapy are often underestimated due to poor patient compliance. Therefore, in our trials, only previously optimally CPAPadherent patients were randomised to either continue or withdraw from CPAP therapy, and a per-protocol analysis was employed, so that a maximal treatment effect could be expected. Thus, the applied study model can be deemed suitable to evaluate physiological and therapeutic effects on BPV.

Despite convincing pathophysiological concepts linking the effects of OSA and their possible influence on BPV $[16,23,24,36]$, previous trials evaluating the effects of CPAP therapy on BPV have come to contradictory conclusions. Altered BPV has been found in previously untreated and otherwise healthy OSA patients [24]. In a recent uncontrolled prospective study, Pengo et al. [29] in- vestigated changes in within-visit variability in office $B P$ in 78 newly diagnosed patients suffering from severe OSA. The analysis was stratified according to whether patients were hypertensive or not. Hypertensive subjects were not treated with antihypertensive medication either prior to or during the intervention period. Patient data were recorded at baseline and again 2 weeks after initiating CPAP therapy. At follow-up, a reduction of within-visit variability in office systolic BP and HR could be detected, and, while observed in both groups, this reduction was more pronounced in the hypertensive patients, most likely reflecting the effect of CPAP therapy on sympathetic activation. Although in our study the majority of the subjects were diagnosed with hypertension, BP in all participants was well controlled, thus possibly masking a larger effect of CPAP withdrawal on systolic BP variability.

In contrast, a randomised placebo-controlled trial of only 41 OSA patients with a respiratory disturbance index $>15 / \mathrm{h}$ could not find a beneficial effect from 1 week of CPAP therapy on BPV [28]. Although a higher respiratory disturbance index and elevated urine norepinephrine were positively related to BPV, there was no significant effect due to therapeutic CPAP versus placebo, since BPV declined equally in both study arms. However, all of these studies were based on a rather small study population. Taking into account the existing evidence from the aforementioned trials $[24,28,29]$, and adding the results of our analysis of randomised controlled trials, the data suggest that CPAP has at most only a minor effect on daytime BPV.

Although we used standardised BP measurement methods to compile the data presented in our study, there are some possible limiting factors. First, the treatment intervention lasted for only 2 weeks. Secondly, analysis of BPV including home measurements of BP relies on patient compliance. Even though the patients were instructed as to when and how to correctly use the measurement device, there was only limited possibility of ensuring the proper conduct of those measurements. While 24-h ambulatory and beat-to-beat BPV provide different pathophysiological information on daytime BPV [37], standardised visit-to-visit office BPV and day-to-day home BPV have been shown to predict outcome in other patient groups and are an accepted method of assessing BPV [11, 38, 39]. Perhaps most importantly, antihypertensive medication is known to have an effect on BPV which depends on the type of medication. Calcium channel blockers and beta-blockers are commonly used to treat hypertension. However, they seem to have opposite effects on $\mathrm{BPV}$, independently of their general effects on mean BP. In contrast to beta-blockers, calcium channel blockers
316

Respiration 2017;93:311-318

DOI: $10.1159 / 000465528$
Lettau/Schwarz/Stradling/Kohler 
have been shown to effectively and consistently reduce BPV [40]. As the patients in this study were asked to continue their medication regimen over the course of the intervention, it is conceivable that despite recurrence of OSA, more distinct changes in BPV may have been masked by medication. In this cohort, all hypertensive subjects were treated, and BP at baseline in these patients was well controlled. On the other hand, whereas in the current study medication was not withheld, in the trial by Bao et al. [28] patients had been taken off antihypertensive medication for 3 weeks prior to the beginning of the study, and still there was no effect of CPAP on BPV.

The results of this study, coming from 4 well-designed randomised controlled trials, provide data regarding CPAP therapy effects on daytime BPV. Despite the lack of evidence of CPAP therapy withdrawal importantly affecting daytime BPV, repetitive nocturnal BP surges up to $80 \mathrm{~mm} \mathrm{Hg}$ seen with OSA due to apnoea- and hypopnoea-associated arousals [41] are abolished by CPAP therapy. Therefore, a long-term beneficial effect on the cardiovascular system from CPAP with regard to BPV may still be possible. Steinhorst et al. [23] recently showed that hypertension is primarily associated with increased night-time BPV rather than daytime BPV. OSA affects cardiovascular regulatory mechanisms most dramatically during sleep, which potentially explains the lack of a strong association between OSA and daytime BPV. The pathophysiology of OSA in hypertension is linked to blunting of the physiological nocturnal dipping pattern of BP and arousal-associated repetitive BP surges, thus possibly having an impact on the development of resistant hypertension in OSA patients [42]. However, the characteristics of BP changes in OSA also include an impaired baroreflex and sustained daytime hypertension, especially in the morning $[43,44]$. Consecutively, we expected morning BPV to be affected by the nocturnal consequences of OSA, an assumption that could not entirely be verified. However, since OSA is common, is often coexistent with a cluster of traditional cardiovascular risk factors, and can be effectively treated, an investigation of the preventive effects of CPAP remains a topic for future long-term trials.

In summary, while within-visit variability in systolic BP slightly increased in response to CPAP therapy withdrawal, the clinical relevance of this change is disputable despite a possible blunting effect of antihypertensive drugs on BPV. In conclusion, it is unlikely that OSA contributes to cardiovascular risk via elevated daytime BPV.

\section{Acknowledgement}

This study was funded by the Swiss National Science Foundation (grants 32003B_124915 and 143365) and the Clinical Research Priority Program (CRPP) Sleep and Health of the University of Zurich.

\section{Financial Disclosure and Conflicts of Interest}

None of the authors has a competing interest regarding this manuscript.

\section{Author Contributions}

Conception and design: all authors; analysis and interpretation of data: E.I.S. and F.L.; drafting of the article: F.L. and E.I.S; revision of the article for important intellectual content and final approval: all authors.

\section{References}

1 Lattimore JD, Celermajer DS, Wilcox I: Obstructive sleep apnea and cardiovascular disease. J Am Coll Cardiol 2003;41:1429-1437.

2 Somers VK, White DP, Amin R, Abraham WT, Costa F, Culebras A, et al: Sleep apnea and cardiovascular disease: an American Heart Association/American College of Cardiology Foundation Scientific Statement from the American Heart Association Council for High Blood Pressure Research Professional Education Committee, Council on Clinical Cardiology, Stroke Council, and Council on Cardiovascular Nursing. In collaboration with the National Heart, Lung, and Blood Institute National Center on Sleep Disorders Research (National Insti- tutes of Health). Circulation 2008;118: 1080-1111.

3 Peppard PE, Young T, Palta M, Skatrud J: Prospective study of the association between sleep-disordered breathing and hypertension. N Engl J Med 2000;342:1378-1384.

4 Nieto FJ, Young TB, Lind BK, Shahar E, Samet JM, Redline S, et al: Association of sleep-disordered breathing, sleep apnea, and hypertension in a large community-based study. Sleep Heart Health Study. JAMA 2000; 283:1829-1836.

5 Marin JM, Carrizo SJ, Vicente E, Agusti AG: Long-term cardiovascular outcomes in men with obstructive sleep apnoea-hypopnoea with or without treatment with continuous positive airway pressure: an observational study. Lancet 2005;365:1046-1053.

6 Redline S, Yenokyan G, Gottlieb DJ, Shahar E, O'Connor GT, Resnick HE, et al: Obstructive sleep apnea-hypopnea and incident stroke: the sleep heart health study. Am J Respir Crit Care Med 2010;182:269-277.

7 Arzt M, Young T, Finn L, Skatrud JB, Bradley TD: Association of sleep-disordered breathing and the occurrence of stroke. Am J Respir Crit Care Med 2005; 172:1447-1451.

8 Bratton DJ, Gaisl T, Wons AM, Kohler M: CPAP versus mandibular advancement devices and blood pressure in patients with obstructive sleep apnea: a systematic review and meta-analysis. JAMA 2015;314:2280-2293.

Blood Pressure Variability in OSA 
9 Lewington S, Clarke R, Qizilbash N, Peto R, Collins R; Prospective Studies Collaboration: Age-specific relevance of usual blood pressure to vascular mortality: a meta-analysis of individual data for one million adults in 61 prospective studies. Lancet 2002;360:1903-1913.

10 Eguchi K, Hoshide S, Schwartz JE, Shimada K, Kario K: Visit-to-visit and ambulatory blood pressure variability as predictors of incident cardiovascular events in patients with hypertension. Am J Hypertens 2012;25:962-968.

11 Rothwell PM, Howard SC, Dolan E, O'Brien E, Dobson JE, Dahlöf B, et al: Prognostic significance of visit-to-visit variability, maximum systolic blood pressure, and episodic hypertension. Lancet 2010;375:895-905.

12 Vishram JK, Dahlöf B, Devereux RB, Ibsen H, Kjeldsen SE, Lindholm LH, et al: Blood pressure variability predicts cardiovascular events independently of traditional cardiovascular risk factors and target organ damage: a LIFE substudy. J Hypertens 2015;33:2422-2430.

13 Rothwell PM: Limitations of the usual bloodpressure hypothesis and importance of variability, instability, and episodic hypertension. Lancet 2010;375:938-948.

14 Hastie CE, Jeemon P, Coleman H, McCallum L, Patel R, Dawson J, et al: Long-term and ultra long-term blood pressure variability during follow-up and mortality in 14,522 patients with hypertension. Hypertension 2013;62: 698-705.

15 Schillaci G, Bilo G, Pucci G, Laurent S, Macquin-Mavier I, Boutouyrie P, et al: Relationship between short-term blood pressure variability and large-artery stiffness in human hypertension: findings from 2 large databases. Hypertension 2012;60:369-377.

16 Kawai T, Ohishi M, Ito N, Onishi M, Takeya Y, Yamamoto K, et al: Alteration of vascular function is an important factor in the correlation between visit-to-visit blood pressure variability and cardiovascular disease. J Hypertens 2013;31:1387-1395; discussion 1395.

17 Darabont R, Tautu OF, Pop D, Fruntelata A, Deaconu A, Onciul S, et al: Visit-to-visit blood pressure variability and arterial stiffness independently predict cardiovascular risk category in a general population: results from the SEPHAR II study. Hellenic J Cardiol 2015;56:208-216.

18 Ip MS, Tse HF, Lam B, Tsang KW, Lam WK: Endothelial function in obstructive sleep apnea and response to treatment. Am J Respir Crit Care Med 2004;169:348-353.

19 Kato M, Roberts-Thomson P, Phillips BG, Haynes WG, Winnicki M, Accurso V, et al: Impairment of endothelium-dependent vasodilation of resistance vessels in patients with obstructive sleep apnea. Circulation 2000; 102:2607-2610.

20 Kohler M, Stoewhas AC, Ayers L, Senn O, Bloch KE, Russi EW, et al: Effects of continuous positive airway pressure therapy withdrawal in patients with obstructive sleep apnea: a randomized controlled trial. Am J Respir Crit Care Med 2011;184:1192-1199.
21 Narkiewicz K, van de Borne PJ, Montano N, Dyken ME, Phillips BG, Somers VK: Contribution of tonic chemoreflex activation to sympathetic activity and blood pressure in patients with obstructive sleep apnea. Circulation 1998;97:943-945.

22 Kohler M, Stradling JR: Mechanisms of vascular damage in obstructive sleep apnea. Nat Rev Cardiol 2010;7:677-685.

23 Steinhorst AP, Gonçalves SC, Oliveira AT, Massierer D, Gus M, Fuchs SC, et al: Influence of sleep apnea severity on blood pressure variability of patients with hypertension. Sleep Breath 2014;18:397-401.

24 Narkiewicz K, Montano N, Cogliati C, van de Borne PJ, Dyken ME, Somers VK: Altered cardiovascular variability in obstructive sleep apnea. Circulation 1998;98:1071-1077.

25 Sharples LD, Clutterbuck-James AL, Glover MJ, Bennett MS, Chadwick R, Pittman MA, et al: Meta-analysis of randomised controlled trials of oral mandibular advancement devices and continuous positive airway pressure for obstructive sleep apnoea-hypopnoea. Sleep Med Rev 2016;27:108-124.

26 Kohler M, Craig S, Pepperell JC, Nicoll D, Bratton DJ, Nunn AJ, et al: CPAP improves endothelial function in patients with minimally symptomatic OSA: results from a subset study of the MOSAIC trial. Chest 2013; 144:896-902.

27 Schwarz EI, Puhan MA, Schlatzer C, Stradling JR, Kohler M: Effect of CPAP therapy on endothelial function in obstructive sleep apnoea: a systematic review and meta-analysis. Respirology 2015;20:889-895.

28 Bao X, Nelesen RA, Loredo JS, Dimsdale JE, Ziegler MG: Blood pressure variability in obstructive sleep apnea: role of sympathetic nervous activity and effect of continuous positive airway pressure. Blood Press Monit 2002;7: 301-307.

29 Pengo MF, Ratneswaran C, Berry M, Kent BD, Kohler M, Rossi GP, et al: Effect of continuous positive airway pressure on blood pressure variability in patients with obstructive sleep apnea. J Clin Hypertens (Greenwich) 2016;18:1180-1184.

30 Rossi VA, Winter B, Rahman NM, Yu LM, Fallon J, Clarenbach CF, et al: The effects of Provent on moderate to severe obstructive sleep apnoea during continuous positive airway pressure therapy withdrawal: a randomised controlled trial. Thorax 2013;68: 854-859.

31 Schwarz EI, Schlatzer C, Stehli J, Kaufmann PA, Bloch KE, Stradling JR, et al: Effect of CPAP withdrawal on myocardial perfusion in OSA: a randomized controlled trial. Respirology 2016;21:1126-1133.

32 Schwarz EI, Martinez-Lozano Sinues P, Bregy L, Gaisl T, Garcia Gomez D, Gaugg MT, et al: Effects of CPAP therapy withdrawal on exhaled breath pattern in obstructive sleep apnoea. Thorax 2016;71:110-117.
33 Hara A, Thijs L, Asayama K, Jacobs L, Wang JG, Staessen JA: Randomised double-blind comparison of placebo and active drugs for effects on risks associated with blood pressure variability in the Systolic Hypertension in Europe trial. PLoS One 2014;9:e103169.

34 Schwarz EI, Schlatzer C, Rossi VA, Stradling JR, Kohler M: The effect of short-term CPAP withdrawal on blood pressure in patients with obstructive sleep apnea: data from three randomized-controlled trials. Chest, in press.

35 Mancia G, Parati G: Clinical significance of "white coat" hypertension. Hypertension 1990; 16:624-626.

36 Deegan PC, McNicholas WT: Pathophysiology of obstructive sleep apnoea. Eur Respir J 1995;8:1161-1178.

37 Webb AJ, Wilson M, Lovett N, Paul N, Fischer U, Rothwell PM: Response of day-today home blood pressure variability by antihypertensive drug class after transient ischemic attack or nondisabling stroke. Stroke 2014;45:2967-2973.

38 Mehlum M, Liestøl K, Julius S, Kjeldsen SE, Hua TA, Rothwell PM, et al: 3D.01: Visit-tovisit blood pressure variability increases risk of stroke or cardiac events in patients given valsartan or amlodipine in the value trial. J Hypertens 2015;33(suppl 1):e40.

39 Hata J, Arima H, Rothwell PM, Woodward $\mathrm{M}$, Zoungas S, Anderson C, et al: Effects of visit-to-visit variability in systolic blood pressure on macrovascular and microvascular complications in patients with type 2 diabetes mellitus: the ADVANCE trial. Circulation 2013;128:1325-1334.

40 Rothwell PM, Howard SC, Dolan E, O'Brien E, Dobson JE, Dahlöf B, et al: Effects of beta blockers and calcium-channel blockers on within-individual variability in blood pressure and risk of stroke. Lancet Neurol 2010;9: 469-480.

41 Ali NJ, Davies RJ, Fleetham JA, Stradling JR: The acute effects of continuous positive airway pressure and oxygen administration on blood pressure during obstructive sleep apnea. Chest 1992;101:1526-1532.

42 Pedrosa RP, Drager LF, Gonzaga CC, Sousa MG, de Paula LK, Amaro AC, et al: Obstructive sleep apnea: the most common secondary cause of hypertension associated with resistant hypertension. Hypertension 2011;58: 811-817.

43 Hla KM, Young T, Finn L, Peppard PE, SzkloCoxe M, Stubbs M: Longitudinal association of sleep-disordered breathing and nondipping of nocturnal blood pressure in the Wisconsin Sleep Cohort Study. Sleep 2008;31: 795-800.

44 Pepperell JC, Ramdassingh-Dow S, Crosthwaite N, Mullins R, Jenkinson C, Stradling JR, et al: Ambulatory blood pressure after therapeutic and subtherapeutic nasal continuous positive airway pressure for obstructive sleep apnoea: a randomised parallel trial. Lancet 2002;359:204-210. 